Letter to the Editor

\title{
Intracameral cefazolin during cataract surgery; antibiotic choice in penicillin 'allergic' patients
}

\author{
Louis J Stevenson MBBS ${ }^{1}$ and Georgia Cleary FRANZCO PhD ${ }^{1,2,3}$
}

1. Royal Victorian Eye and Ear Hospital, 32 Gisborne Street, East Melbourne, Victoria, Australia, 3002

2. Centre for Eye Research Australia, 32 Gisborne Street, East Melbourne, Victoria, Australia, 3002

3. University of Melbourne, Parkville, Victoria, Australia, 3010

Correspondence: Dr Louis Stevenson, Royal Victorian Eye and Ear Hospital, 32

Gisborne Street, East Melbourne VIC, Australia

Email: louis.stevenson@utas.edu.au

Received 9 February 2019; accepted 16 February 2019

Funding sources / Financial disclosure: None

Conflict of interest: None

\section{Data sharing and data accessibility statement}

Data are available upon reasonable request made to the corresponding author. The Human Research Ethics Committee at the Royal Victorian Eye and Ear Hospital will be consulted throughout this process to ensure that all legal and ethical obligations are met.

This is the author manuscript accepted for publication and has undergone full peer review but has not been through the copyediting, typesetting, pagination and proofreading process, which may lead to differences between this version and the Version of Record. Please cite this article as doi: $10.1111 /$ ceo.13486

This article is protected by copyright. All rights reserved. 
Intracameral antibiotics are used during cataract surgery to prevent post-operative endophthalmitis. The European Society of Cataract and Refractive Surgeons (ESCRS) endophthalmitis study was a landmark publication demonstrating a five-fold reduction in the rate of post-operative endophthalmitis with intracameral cefuroxime, when compared to patients who received no intracameral antibiotics. ${ }^{1}$

Intracameral cefuroxime is not licenced in Australia and therefore not available for use. As such, intracameral cefazolin (ICC), a $1^{\text {st }}$ generation cephalosporin, is used in place of cefuroxime at the Royal Victorian Eye and Ear Hospital (RVEEH). It has excellent coverage against gram-positive organisms and its efficacy has been established for this indication. ${ }^{2}$ Unfortunately, ICC is withheld unnecessarily in some patients due to undue concerns regarding hypersensitivity in penicillin 'allergic' patients.

A retrospective audit of ICC use in cataract surgery at the RVEEH was performed to assess the size of this problem. Ethics approval was obtained from the RVEEH Human Research Ethics Committee. Electronic medical records of 999 consecutive patients undergoing routine cataract surgery between December 2017 and February 2018 were reviewed. ICC use was documented in $92.3 \%$ of cases. Seventy-seven patients did not receive ICC; of these cases pre-operative documentation of Type 1 and non-Type 1 penicillin hypersensitivity reactions were present in 12 and 9 patients, respectively. Eight had a history of cephalosporin sensitivity. It was unclear why the remaining 48 patients did not receive ICC.

Of the 40 patients with pre-operative documentation of a Type 1 hypersensitivity to penicillin, 70\% received ICC. Eighty-six percent of patients with pre-operative documentation of a non-Type 1 reaction to penicillin received ICC. No cases of anaphylaxis, or any other Type 1 hypersensitivity to ICC occurred in this series. 
It is important that ophthalmologists are aware of the features of serious allergic reactions, termed Type 1 hypersensitivities, so they can differentiate these from non-specific drug reactions. Type 1 hypersensitivity reactions are characterised by pruritus, urticarial rashes, angioedema, airway compromise, respiratory distress, hypotension, vomiting and diarrhoea. These manifestations occur within one hour of drug exposure. ${ }^{3}$

Fortunately, anaphylaxis to cephalosporins is rare and there are only two case reports of anaphylaxis following intracameral cephalosporin administration, and none specifically after intracameral cefazolin. Despite this, there is concern surrounding the use of cephalosporins in patients who are hypersensitive to penicillins due to an overestimated risk of cross-reactivity.

Penicillins and cephalosporins belong to the beta-lactam group of antibiotics. Crossreactivity is most commonly mediated by the $\mathrm{R} 1$ side chains common to their molecular structure (Figure 1). The greatest risk of cross reactivity occurs when patients allergic to a penicillin are exposed to a cephalosporin that contains a similar or identical R1 side chain. Importantly, the R1 sidechain found in cefazolin is structurally distinct from penicillins, enhancing its safety profile. ${ }^{4}$

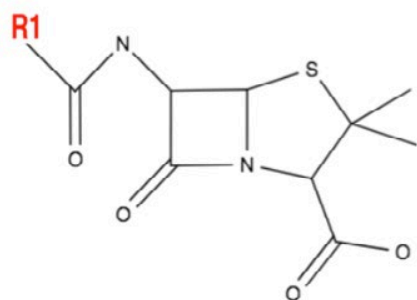

Penicillin

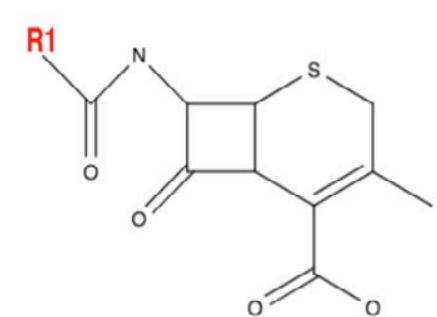

Cephalosporin 
Figure 1: Chemical structure of penicillin (left) and cephalosporin (right) with the R1 side chain highlighted in red.

Penicillin allergy is overestimated in the community. Only $10 \%$ of patients selfreporting a penicillin "allergy" are found to be truly hypersensitive when formally tested. ${ }^{5}$ It was previously taught that the cross reactivity rate between penicillins and cephalosporins was 10\%; this figure is now considered to be myth due to significant limitations in the data that produced these figures. As such, the true rate of cross reactivity in patients self-reporting a penicillin hypersensitivity is now thought to be approximately $1 \% .^{5}$ From this it can be seen that the risk posed by ICC to patients who self-report a penicillin allergy is very low.

The omission of ICC during cataract surgery increases the risk of post-operative endophthalmitis. When assessing a patient with a history of penicillin "allergy", we propose that ophthalmologists begin by taking a further history to determine if the nature of the reaction is consistent with a Type 1 hypersensitivity. Where this is not the case, all patients should receive ICC. Where this is the case, clinicians should remember that the risk of cross reactivity is low and strongly consider using ICC. 


\section{REFERENCES}

1. Barry P, Seal DV, Gettinby G, Lees F, Peterson M, Revie CW, et al. ESCRS study of prophylaxis of postoperative endophthalmitis after cataract surgery: Preliminary report of principal results from a European multicenter study. J Cataract Refract Surg. 2006;32(3):407-10.

2. Tan CSH, Wong HK, Yang FP. Epidemiology of postoperative endophthalmitis in an Asian population: 11-year incidence and effect of intracameral antibiotic agents. J Cataract Refract Surg. 2012;38(3):425-30.

3. Kemp SF, Lockey RF, Wolf BL, Lieberman P. Anaphylaxis A Review of 266 Cases. Arch Intern Med. 1995;155(16):1749-54.

4. Benninger MS. Cephalosporin use in treatment of patients with penicillin allergies. J Am Pharm Assoc. 2008;48(4):530-40.

5. Campagna JD, Bond MC, Schabelman E, Hayes BD. The use of cephalosporins in penicillin-allergic patients: a literature review. J Emerg Med. 2012;42(5):612-20. 


\section{University Library}

\section{- M M N E R VA A gateway to Melbourne's research publications}

Minerva Access is the Institutional Repository of The University of Melbourne

Author/s:

Stevenson, LJ;Cleary, G

Title:

Intracameral cefazolin during cataract surgery: Antibiotic choice in penicillin "allergic" patients

Date:

2019-08-01

Citation:

Stevenson, L. J. \& Cleary, G. (2019). Intracameral cefazolin during cataract surgery: Antibiotic choice in penicillin "allergic" patients. CLINICAL AND EXPERIMENTAL OPHTHALMOLOGY, 47 (6), pp.803-804. https://doi.org/10.1111/ceo.13486.

Persistent Link:

http://hdl.handle.net/11343/285639 